\title{
Diva Noronha e os saberes profissionais de matemática para a formação de professores em tempos da Reforma Curricular do Rio de Janeiro (1970-1983)
}

Diva Noronha and the professional knowledge of mathematics for the formation of teachers in times of the

Curricular Reform of Rio de Janeiro (1970-1983)

Diva Noronha y el conocimiento profesional de las matemáticas para la formación de profesores en tiempos de la Reforma Curricular de Río de Janeiro (1970-1983)

Thiago Sousa Cunha

Universidade do Estado do Rio de Janeiro, Campus Maracanã

Rio de Janeiro, Brasil

E-mail: sousa thi@outlook.com

Orcid: 0000-0003-0242-2496

Guilherme Antônio Santos da Silva Universidade do Estado do Rio de Janeiro, Campus Maracanã

Rio de Janeiro, Brasil

E-mail: guilhermea.s.s@outlook.com

Orcid: 0000-0001-9366-8680

Denise Medina França Universidade do Estado do Rio de Janeiro, Campus Maracanã

Rio de Janeiro, Brasil E-mail: denisemedinafranca@gmail.com

Orcid: 0000-0002-1649-5816

Resumo: Apresentamos considerações iniciais sobre o processo de produção de saberes docentes sistematizados por Diva Noronha nas publicações dirigidas a professores do Laboratório de Currículos (LC) do estado do Rio de Janeiro, no período de implementação da reformulação curricular de matemática do Estado, a partir da 
década de 1970 até o encerramento das atividades do LC. Adotamos os conceitos: expert, saberes a ensinar e saberes para ensinar para auxiliar nas análises do material selecionado no período de funcionamento do LC. Assim, as primeiras considerações nos permitem caracterizar Noronha como uma possível expert para a formação de professores das séries iniciais. Apontamos, ainda, a produção de saberes docentes com influência da psicologia e pedagogia e as orientações para professores que revelam uma matemática para ensinar cognitivista, respeitando o desenvolvimento mental das crianças.

Palavras-chave: História educação matemática. Expertise. Diva Noronha.

Abstract: We hereby present some initial concerns on the production process of teaching knowledge, systematized by Diva Noronha through the publications addressed to teachers of the Curriculum Laboratory (LC) of the state of Rio de Janeiro, in the period of the implementation of the state's curriculum reformulation of mathematics from the 1970's until the end of LC's activities. The following concepts were adopted: expert, knowledge to be taught and knowledge to teach, to assist in the analysis of the selected material during the period of operation of the LC. Thus, the first considerations allow us to characterize Noronha as a possible expert for the training of teachers in the initial grades. We also point out the production of teaching knowledge with the influence of psychology and pedagogy and guidelines for teachers that reveal a mathematics to teach cognitivist, respecting the mental development of children.

Keywords: History mathematics education. Expert. Diva Noronha.

Resumen: Presentamos consideraciones iniciales sobre el proceso de producción de conocimiento didáctico sistematizado por Diva Noronha en las publicaciones dirigidas a los profesores del Laboratorio de Currículo (LC) del estado de Río de Janeiro, en el período de implementación de la reformulación del currículo estatal de matemáticas desde la década de 1970, hasta el cierre de las actividades del LC. Adoptamos los conceptos: experto, conocimiento para enseñar y conocimiento para enseñar para ayudar en el análisis del material seleccionado en el periodo de funcionamiento del LC. Así, las primeras consideraciones nos permiten caracterizar a Noronha como una posible experta para la formación de profesores de series iniciales. También señalamos la producción de conocimiento didáctico con influencia de la psicología y la pedagogía y las directrices del profesorado que revelan una matemática para enseñar cognitivista, respetando el desarrollo mental de los niños.

Palabras-chave: Educación matemática en la historia. Expert. Diva Noronha.

Recebido em 29/01/2021

Aceito em 04/03/2021 


\section{INTRODUÇÃO}

Esta investigação é guiada a partir do relato de experiência concedido por Diva Noronha através de uma videoconferência (Live, 2020), dos jornais Correio da Manhã (1971) e O Fluminense $(1970,1971)$, leitura de texto de França e Maciel (2020) e a tese de Noronha (1980). O objetivo é discutir considerações iniciais sobre o processo de produção de saberes docentes sistematizados por Diva Noronha nas publicações dirigidas a professores do Laboratório de Currículos (LC) do estado do Rio de Janeiro", no período de implementação da reforma curricular de matemática do estado, a partir da década de 1970 até o encerramento das atividades do LC. Procuramos construir um cenário indicando as etapas de implementação instituídas após a efetivação da Lei n. 5.692 (1971) - Lei de Diretrizes e Bases da Educação Nacional (LDB)².

De acordo com Faria e Lobo (2005) as mudanças no sistema de ensino do Brasil fizeram-se necessárias, pois a educação vivenciava um estado crítico, especificamente no Rio de Janeiro, visto a necessidade de homogeneização de propostas de ensino para o novo estado, criado a partir da fusão ${ }^{3}$.

Neste contexto, entrelaçamos as fontes a que tivemos acesso até então: os relatos concedidos por Noronha (Live, 2020), os noticiários de Correio da Manhã (1971) e O Fluminense $(1970,1971)$ coletados na Hemeroteca Digital Brasileira ${ }^{4}$, sobre as seguintes palavras-chave: "Laboratório de Currículo" e "Reforma Curricular" com o propósito de observar a situação da educação no estado do Rio de Janeiro, indicando

\footnotetext{
${ }^{1}$ O Presidente Ernesto Geisel sancionou, em 1o de julho de 1974, a lei que estabeleceu a criação de novos Estados e Territórios e fixou disposições para a fusão dos Estados da Guanabara e Rio de Janeiro a partir de 15 de março de 1975. Os dois Estados passam a se constituir em um só, com o nome de Estado do Rio de Janeiro (França \& Maciel, 2020).

2 Modificou a estrutura de ensino do país, na qual o curso primário e o antigo ginásio se tornaram um só curso de $1^{\circ}$ grau. Foi uma lei promulgada no contexto da ditadura civil-militar e que trouxe permanências e mudanças nas concepções de educação que vinham se desenhando no período (França, 2019).

${ }^{3}$ Para compreender melhor as mudanças ocorridas no espaço geográfico do que significou e hoje significa Estado do Rio de Janeiro: de 1891 a 1960, a cidade do Rio de Janeiro denominava-se Distrito Federal, de 1960 até 1974, Estado da Guanabara e finalmente a partir de 1974 houve a fusão do Estado da Guanabara com o Estado do Rio de Janeiro, passando a ser o Estado do Rio de Janeiro (Villela, Lacava, Costa, Franca, \& Salvador, 2016).

${ }^{4}$ Disponível em https://bndigital.bn.gov.br/hemeroteca-digital/.
} 


\section{Universidade Federal da Grande Dourados}

a presença do tema nas preocupações e a cobrança da sociedade por soluções dos problemas.

Sabendo que há várias discussões sobre o conceito de experts, ponderamos a afirmação de Borry (2020): os experts constituem uma entidade quase indefinível, entretanto essencial em nosso estilo de vida atual. Ademais, o expert consegue fazer o diagnóstico de um problema, visto que já vivenciou situações similares tendo uma representação holística que propicia fazer conexões úteis, em razão de sua efetiva atuação no campo.

Para Hofstetter, Schneuwly e Freymond (2017) a expertise é vista como uma ação do especialista em educação em uma instituição, aliando saberes da profissão com os da disciplina acadêmica. Assim, a expertise que consideraremos está ligada à produção de saberes para professores durante o período da reforma curricular do Estado do Rio de Janeiro, em que Noronha trabalhou na formação de professores de matemática da rede estadual de ensino do Rio de Janeiro.

A expertise é condição fundamental para a convocação do especialista pelo Estado para resolver problemas técnicos. A esse especialista atribui-se o nome de expert e, como identificado por França (2020), para que seja categorizado como tal, necessita cumprir as seguintes condições: participação em uma função no aparelho estatal por indicação política, social, educacional; reconhecimento pelos pares - ter recebido destaque por um grupo de professores, associações ou instituições de ensino, revistas ou jornais especializados; sistematização e objetivação de saberes; circulação dos saberes produzidos.

Para a verificação da condição de Noronha como expert, trazemos as ideias de Valente (2019) para o diálogo. O autor, apropriando-se dos conceitos saberes a ensinar e saberes para ensinar postos por Hofstetter et al. (2017), estabeleceu a hipótese teórica de que o saber profissional do professor que ensina matemática é formado por dois conjuntos de saberes, quais sejam: a matemática a ensinar e a matemática para ensinar. Dessa forma, a primeira "refere-se à matemática como objeto de ensino do professor; o que ele tem que ensinar" (p. 18), que se origina do 


\section{Universidade Federal da Grande Dourados}

campo disciplinar matemático, e a segunda "leva em conta a formação de professores" (p. 18), "indica o instrumento para esse ensino, uma ferramenta, portanto" (p. 21).

Dessa forma, este estudo norteia-se por três questões: De que maneira Diva Noronha colaborou para a produção de saberes profissionais docentes para os professores das séries iniciais no Laboratório de Currículos (LC) do estado do Rio de Janeiro? Que contextos de sustentação possibilitaram as propostas de Noronha? Quais as propostas gerais de Noronha?

Diante deste cenário, propomos e elaboramos um estudo, desenvolvido pelo GHEMAT-Rio ${ }^{5}$ que se justifica pela necessidade de debater sobre questões referentes à formação didático-metodológica de professores das séries iniciais em matemática. Vê-se, assim, que há um possível fundamento em termos da historicidade da formação do professor no espaço geográfico que tomamos neste projeto que abarca o estado do Rio de Janeiro e que nos parece, no intervalo temporal em estudo, ser fértil para nossa reflexão.

Nossas primeiras considerações indicam que Diva Noronha, professora do estado do Rio de Janeiro, tornou-se reconhecida por seus pares, de tal maneira que suas experiências docentes foram sistematizadas e circularam em forma de cursos de aperfeiçoamento para professores do ensino primário6; além disso, também desempenhou uma função governamental. Dessa forma, isso a caracterizaria como uma possível expert para a formação de professores.

\section{O CENÁRIO: A EDUCAÇÃO NO ESTADO DO RIO DE JANEIRO (DÉCADA DE 1970)}

O jornal Correio da Manhã, em sua edição de 1 de março de 1971, trouxe detalhes sobre "evasão, reprovação, falta de condições materiais, deficiência dos currículos e o despreparo das professôras"7 na escola primária, publicando um relatório elaborado pelo Instituto Nacional de Estudos e Pesquisas (INEP), com a finalidade de subsidiar

\footnotetext{
${ }^{5}$ Os participantes do GHEMAT-Rio pertencem a diferentes atividades de ensino: estudantes de iniciação científica, mestrado, doutorado e professores da rede pública.

${ }^{6}$ Hoje corresponde ao primeiro segmento do ensino fundamental.

${ }^{7}$ Utilizamos a expressão posta no jornal.
} 


\section{Universidade Federal da Grande Dourados}

o grupo de estudo do projeto que discutia a Lei 5.692, que seria aprovada apenas em agosto de 1971, com a promessa de sua implementação completa até 1972.

Conforme o relatório publicado, a pesquisa do INEP na época constatava que:

Funcionam no Brasil, atualmente, 135 mil escolas primárias. Dessas, cêrca de 95 têm apenas uma sala de aula para todas as turmas, de todos os níveis. São 13,6 milhões de crianças matriculadas, sendo que, só no primeiro ano, 37\% são reprovadas. (Correio da Manhã, 1971)

O relatório anunciou, de acordo com a pesquisa realizada, que a modificação prevista nessa lei, abolindo o sistema de passagem do primário para o ginásio ${ }^{8}$, não seria suficiente para resolver a problemática das evasões, listando três "defeitos essenciais" que precisariam ser corrigidos: "currículos mal feitos, professores despreparados e pequena duração dos cursos".

Conforme o relatório, também, após um estudo comparativo dos currículos escolares brasileiros com o de países como Estados Unidos, França, União Soviética, Suíça, Suécia, Itália e Bélgica, observou-se que seria necessário adaptar os programas do curso primário, de maneira que eles correspondessem ao que a criança seria capaz de aprender, não ao que ela deveria aprender. Outra verificação relevante desse estudo foi que enquanto os professores brasileiros possuíam formação secundária, os de outros países tinham formação universitária.

O relatório considerou, então, que nossos programas não poderiam fazer as mesmas exigências dos países anteriormente citados, visto que eles tinham mais tempo para abordar o mesmo conteúdo, e exemplificou sua argumentação ao comparar os saberes matemáticos de referência para o ensino primário no Brasil e em outros países:

No programa de matemática, enquanto no Brasil o primeiro ano prevê no estudo da numeração, o limite de 100 , em outros países como a Suíça, o aluno de $1^{\circ}$ ano trabalha com números até 10 e na Itália e na Bélgica até 12 . As contas de multiplicação que são aprendidas pelas crianças do $2^{\circ}$ ano primário e às vezes até pelas do $1^{\circ}$ ano são ensinadas apenas no $4^{\circ}$ ano, nas escolas da Suíça e

\footnotetext{
${ }^{8}$ Hoje corresponde do $6^{\circ}$ ao $9^{\circ}$ ano do ensino fundamental.
} 
dos Estados Unidos. Na Itália foi realizado um estudo sobre o domínio dos conhecimentos de fração já no ensino médio onde se verificou que o domínio das operações com frações só é obtido no $3^{\circ}$ ou $4^{\circ}$ ano dos cursos médios. A introdução da noção de número decimal, que aqui é feita no $3^{\circ}$ ano, é realizada no 4ํㅡㄴ na Itália e na Bélgica e no $5^{\circ}$ em Genebra, na Suíça e em Columbia nos Estados Unidos. Em Nova York só é feita no 6ํano escolar. (Correio da Manhã, 1971)

O relatório, ainda, discute sobre os professores "despreparados", pois, segundo o Censo Escolar realizado naquele período, o magistério primário era constituído por aproximadamente $50 \%$ dos professores com formação incompleta, os nomeados "docentes leigos". A pesquisa do Inep foi realizada em 85 das consideradas insuficientes 2000 escolas normais, nas quais se observaram deficiências nos cursos de formação:

Os cursos normais, na maioria, não oferecem aos professores oportunidades eficientes de prática e observação de aulas. Alguns não mantêm escolas de aplicação e outros têm leigos em seus quadros. Outra agravante: além de insuficiência no número de escolas e na formação dos profissionais, a pesquisa revelou que muitos nunca chegam a exercer a profissão e outros somente a exercem com a intenção de financiar um curso universitário. (Correio da Manhã, 1971)

Nessa pesquisa, a faixa-etária média de idade dos professores primários estaduais e municipais era de 20 a 29 anos, em sua maioria do sexo feminino, que recebiam, pela média de 4 a 5 horas diárias de trabalho, de 1 a 2 salários mínimos ${ }^{9}$ em nível estadual e menos de 1/2 salário mínimo em nível municipal. Os índices relatados foram justificados por: "Ausência de formação pedagógica específica para o magistério; baixos salários; insuficiente instrução dos professores; grande dependência financeira; falta de curso de aperfeiçoamento e a falta de critério para promoção ministerial" (Correio da Manhã, 1971).

\footnotetext{
${ }^{9}$ Decreto ํㅡ 68576, de 1971, determinava que a partir de maio de 1971 o salário mínimo seria de Cr\$ 225,60. De acordo com o DIEESE - Departamento Intersindical de Estatística e Estudos Socioeconômicos, uma cesta básica na época valia aproximadamente $\operatorname{Cr} \$ 105,08$.
} 


\section{Universidade Federal da Grande Dourados}

Ainda, segundo o Correio da Manhã (1971), as estatísticas da UNESCO ${ }^{10}$ coletadas no período da pesquisa mostravam que 5 anos de estudo numa escola primária brasileira correspondiam a aproximadamente 3.950 horas de aula, caso a escola seguisse o regime de dois períodos por dia e 22 horas semanais. Em comparação, para estes mesmos anos, em países desenvolvidos como França, Inglaterra, Estados Unidos e Suíça, o total de horas de aula nunca ficava abaixo de 5.500 .

Diante do cenário, a reforma curricular do Rio de Janeiro era iminente e urgente, devendo criar condições socioeconômicas para o profissional docente e para os futuros profissionais no seu ambiente de estudo, pois o baixo índice de profissionalização do magistério brasileiro, de acordo com a pesquisa, era o principal agravante dos problemas do ensino primário. Também, com a responsabilidade pela implementação da Lei 5.692 (1971) no Estado, aliada aos problemas oriundos da fusão do estado do Rio de Janeiro com o estado da Guanabara, era necessário convocar especialistas que trouxessem soluções e, mais ainda, com respaldo da comunidade escolar para aceitar as reformas propostas.

Antes mesmo de entrar em vigor, a implementação da reforma dos sistemas de ensino deliberados nessa lei iniciou-se em caráter experimental em algumas escolas do Brasil, escolhidas pelo Conselho Federal de Educação.

Foi o caso da Escola Experimental da Lapa de São Paulo"11, conhecida pelas experiências educacionais. Desse modo, a escola de 2000 alunos, em média, recebeu 250 técnicos em educação como psicólogos, sociólogos, técnicos em comunicação, professores e sanitaristas, considerando-se que, conforme os resultados das conclusões obtidas pela aplicação das experiências, os métodos deste colégio poderiam ser aplicados a todos os colégios da rede pública (Correio da Manhã, 1971).

Para se adequar à nova estrutura de ensino, o colégio experimental da Lapa precisou adequar a sua estrutura física, construindo salas especiais com instalações

\footnotetext{
${ }^{10}$ Organização das Nações Unidas para a Educação, a Ciência e a Cultura

${ }^{11}$ A Escola implantou um projeto educacional integrado, que formava o aluno ao longo dos 11 anos e que compreendia a pré-escola, o primário e o ginásio (hoje educação infantil e ensino fundamental), a equipe da escola e a própria comunidade (França, 2019).
} 
bem simples como "salas de artes plásticas, de artes industriais, uma cozinha para educação doméstica, um laboratório de ciências, um laboratório de recursos audiovisuais e uma biblioteca" (Correio da Manhã, 1971).

No Rio de Janeiro, a escola selecionada para experiências educacionais foi o Centro Educacional de Niterói - CEN, localizado na capital estadual fluminense e coordenado pela diretora Myrthes de Luca Wenzel ${ }^{12}$.

Segundo o jornal O Fluminense (1970), podemos observar que, anteriormente à reforma, o CEN já usava uma proposta de ensino voltada tanto para o conhecimento do cotidiano dos alunos quanto para sua individualidade. Em entrevista, a diretora Wenzel relatou o foco principal do novo currículo do CEN:

A linguagem é o ponto de partida para a estruturação do currículo do CEN. Esta visão eminentemente linguística do processo de conhecimento constituirá a base metodológica em que se baseará o ensino nas primeiras séries do primeiro grau, quando apenas um professor se encarregará do ensino da Linguagem e a Matemática poderá surgir como língua segunda. (O Fluminense, 1971)

Para identificar que novos saberes foram produzidos pelas escolas experimentais, que subsidiaram a elaboração de propostas para o LC, a visão de Wenzel é importante para o nosso estudo, já que, tempos depois, como secretária de educação do Rio de Janeiro, criaria o LC, convocando uma equipe de especialistas, com a finalidade de produção de saberes, acordados nas propostas da reforma, e sistematizados nas publicações do LC.

É importante ressaltar aqui o apoio que esta proposta buscou nos princípios linguísticos - da Lógica matemática - do desenvolvimento das estruturas vivenciais, a partir da Psicanálise, além dos princípios da Epistemologia Genética. A inteligência se constrói a partir da ação que o indivíduo realiza sobre o meio. Essa ação consiste num movimento contínuo em busca de equilíbrio das suas funções básicas do organismo: assimilação e acomodação. (Rio de Janeiro, 1976, p. 27)

${ }^{12}$ Dois grandes momentos marcaram a sua vida de educadora: a criação do Centro Educacional de Niterói, Escola Experimental da Fundação Brasileira de Educação, em 1960, do qual foi Diretora Fundadora; e a participação no Governo, na fusão dos Estados do Rio e Guanabara, como Secretária de Estado de Educação e Cultura (conforme http://alerjln1.alerj.rj.gov.br/) 


\section{Universidade Federal da Grande Dourados}

Como a proposta estabelecia a fundamentação nas teorias psicogenéticas de Piaget ${ }^{13}$, o enfoque principal para a criação dos novos programas foi de se voltarem inteiramente para as especificidades e necessidades dos alunos, ativando suas estruturas mentais, no tempo de cada indivíduo e também da escola, além de serem adequados às peculiaridades regionais, fornecendo, assim, um roteiro básico aos professores, ou seja, com prescrições aos professores de como ensinar.

\section{A CRIAÇÃo do LABORATÓRIO DE CURRículos}

No dia 15 de março de 1975, Wenzel assumiu a secretaria de educação do Rio de Janeiro, já colocando em prática todos os ideais para a reforma na educação do Estado. Em sua primeira reunião anual com os secretários de educação dos estados do Brasil, ela defendeu, como possível solução para os problemas do ensino, a regionalização da educação e da cultura, procurando soluções específicas para cada região. Desse modo, avaliando que parte dos problemas da educação estava nos programas das escolas, Wenzel decidiu criar um projeto diretamente responsável pela mudança e renovação: o Laboratório de Currículos.

Sustentando suas ideias na teoria da linguística transformacionista de Noam Chomsky ${ }^{14}$ e seguindo fielmente a concepção de Piaget, que explica o "processo de desenvolvimento cognitivo", Wenzel nomeou Circe Navarro Rivas como a primeira diretora para o projeto, incumbida de formar uma equipe preparada para debater sobre as necessidades da mudança curricular.

Essa equipe era formada por professores do Estado, que já possuíam um trabalho notável nas suas escolas; também, alguns desses professores faziam parte do Programa de Pós-Graduação em Educação da Fundação Getúlio Vargas, onde a própria Circe Navarro Rivas era docente. Diva Noronha foi, então, nomeada para

\footnotetext{
${ }^{13}$ Biólogo, Psicólogo e Epistemológico suíço que revolucionou o modo de enfrentar a educação de crianças ao mostrar que elas constroem o próprio aprendizado e que não pensam como os adultos.

${ }^{14}$ Professor emérito em Linguística no Instituto de Tecnologia de Massachusetts, é também o autor de trabalhos fundamentais sobre as propriedades matemáticas das linguagens formais, postulando que se podem descrever algebricamente as línguas, ou melhor, a língua humana, a partir de esquemas abstratos. (Leia mais em: https://super.abril.com.br/cultura/dentro-da-cabeca-de-noam-chomsky)
} 


\section{Universidade Federal da Grande Dourados}

coordenar a equipe de matemática para as séries iniciais, com o papel de elaborar documentos, orientando e formando professores para implementar as novas propostas da reforma.

De acordo com o relato de Noronha (Live, 2020), a equipe de matemática voltada para as séries iniciais do LC era constituída por Leila Alcure Pereira, Maria José Montes, Luiz Antonio Garcia e por ela própria. Todos eles dividiam as responsabilidades, refletindo sobre suas experiências docentes, com a finalidade de desenvolver ideias sobre o que poderia ser proposto para o ensino de matemática. As reuniões ocorriam semanalmente, para discussão e avaliação dos cursos de formação ministrados, incluindo comentários dos participantes sobre as atividades propostas e os encaminhamentos para viabilizar as novas propostas de formação para os professores da rede do estado. Noronha ressalta que a produção de documentos indicando o processo de produção de saberes nessas reuniões foi prejudicado pela falta de tempo da equipe, sendo, pela facilidade que tinham para se entenderem usando poucas "letras", as anotações feitas em qualquer papel ou canto de página.

\section{QUEM FOI Diva NORONHA?}

Diva Maria Bretas de Noronha nasceu em 29 de janeiro de 1937 em Niterói, no Rio de Janeiro. Graduou-se bacharel em Matemática em 1961 e em Licenciatura em 1962, pela Pontifícia Universidade Católica do Rio de Janeiro (PUC-Rio). Devido à extinção do curso, foi transferida para a Universidade Santa Úrsula (USU) e, por meio de um convênio entre as instituições católicas, foi agraciada com uma bolsa de estudos na Universidade de Louvain, na Bélgica, em 1961 (Ramos, 2011).

O curso de extensão em Louvain terminou em 1962. Em 1965, Noronha iniciou sua trajetória profissional como professora no Colégio Pedro II, convidada pelo Professor Haroldo Lisboa (professor do CPII) e ali permaneceu até 1968, quando foi aprovada em um concurso público para professora da rede do estado da Guanabara. Durante esse período, conquistou outra bolsa concedida pelo governo francês para estagiar no Instituto de Pesquisa em Educação Matemática (IREM) de Lyon nos anos 1972 e 1973. Além disso, atuou também como professora da Secretaria de Estado de 
Educação do Rio de Janeiro (SEEC/RJ) e da Associação Fluminense de Educação e, como professora convidada, no curso de especialização em Ensino de Ciências da Universidade do Estado do Rio de Janeiro (UERJ) em 1989.

Em 1980, tornou-se mestre em Ensino de Ciências e Matemática pela Universidade Estadual de Campinas (Unicamp), orientada por Sérgio Lorenzato, defendendo a dissertação chamada de: "Proposta de solução para atualização dos professores da rede estadual de ensino do Rio de Janeiro em matemática, utilizando vídeo-tape". Durante o seu mestrado, a convite do professor Ubiratan D'Ambrosio, Diva cursou na Unicamp uma disciplina que a fez conhecer o Instituto de Epistemologia e relata que lá: "As pessoas se prendiam na faixa etária para definir a fase da pessoa e só depois se percebeu que o encadeamento que vale, ou seja, alguns grupos chegam ao conhecimento mais cedo e outros mais tarde" (Live, 2020).

Segundo Noronha, todos os que realizaram esse mestrado na Unicamp tinham um compromisso com as suas secretarias ou países para desenvolverem alguma técnica que melhorasse a educação, fato que tornou o mestrado bem produtivo para todos, devido à troca de experiências e de soluções para a educação. No seu caso específico, a busca por uma solução para implementar a proposta metodológica para o Laboratório de Currículos (Live, 2020).

Podemos dizer que os saberes docentes produzidos por Noronha e repercutidos nos cursos de formação de professores para rede pública, ministrados por ela, proporcionaram prestígio em seu campo. As oportunidades de vivências, principalmente as da Europa, e do contato com a literatura científica na participação em cursos e congressos possibilitaram a produção de saberes docentes para as séries iniciais, necessários às novas propostas. Estes saberes passaram a circular em cursos de formação de professores.

Assim, por sua expertise, Noronha foi convocada pelo estado do Rio de Janeiro em 1975 para chefiar a equipe de matemática das séries iniciais e, posteriormente, integrou a equipe que elaborou a estruturação do ensino primário do Colégio Pedro II, o Pedrinho, primeiro segmento do ensino fundamental. 


\section{Universidade Federal da Grande Dourados}

Para Noronha, o sucesso da implementação das propostas do LC perpassou principalmente pela atuação do professor. Como exemplo, afirma que, para trabalhar na abordagem de uma matemática estruturalista fundamentada nas relações, era necessário propiciar situações variadas utilizando material concreto para que essas relações fossem concretizadas. Dentre os materiais utilizados, estavam: caixinha de fósforo, semente de pinha, saquinho amarrado com fita colorida, papel, etc. Para ela, a diversidade dos materiais era imprescindível para que o aluno se sentisse desafiado e motivado a tirar daquele material alguma abstração; caso contrário, o aluno estaria apenas aprendendo a utilizar o material e não o conteúdo em si (Live, 2000).

Outro ponto defendido por Noronha foi de que, ao preencher uma tabela, não importava como o aluno ordenava os algarismos, tanto da direita para a esquerda quanto ao contrário, pois isso não demonstrava se o aluno tinha aprendido ou não (Live, 2000). Para a época, esses pensamentos e concepções eram muito exclusivos, pois a maioria do professorado tinha um ensino mecanizado e o aluno deveria sempre reproduzir o que foi ensinado, e não refletir sobre aquilo.

Noronha também produziu materiais didáticos que estavam em total acordo com os ideais propostos pelo LC e pelo que defendiam Piaget e Dienes, sendo a área de desenvolvimento de inteligência e autonomia do raciocínio o principal foco de seu trabalho.

\section{O PAPEl DE Diva NORONHA NO LABORATÓRIO DE CURRÍ́culos}

Conforme relato de sua experiência (Live, 2020), o trabalho no LC foi iniciado com visitas a escolas em classes de alfabetização, primeiras e segundas séries com 0 intuito de apresentar materiais concretos que poderiam ser utilizados nas atividades propostas. Os referidos materiais eram confeccionados pela própria equipe e as apostilas, depois de elaboradas, eram datilografadas por um funcionário do Estado para serem distribuídas nas reuniões de formação de professores.

Enquanto esteve na equipe do LC, um dos seus papéis, assim como dos demais, era treinar polos experimentais, ou seja, formar professores para trabalhar com os saberes docentes produzidos, além de observar nas escolas se esses professores 
estavam aplicando, aos alunos em sala de aula, o que fora ensinado. Segundo ela, vale frisar que esses materiais não eram repetidos e "tudo que fosse apoiado no Piaget e Dienes nós usávamos; classificação e seriação, fazíamos com as letras e palavras durante o ensino de matemática" (Live, 2020).

Essa fala de Noronha pode ser comprovada analisando-se a publicação do LC (Rio de Janeiro, 1976), em que há citações que corroboram as ideias de Piaget e Dienes, visto que são propostas atividades de seriação e classificação com a utilização de material concreto.

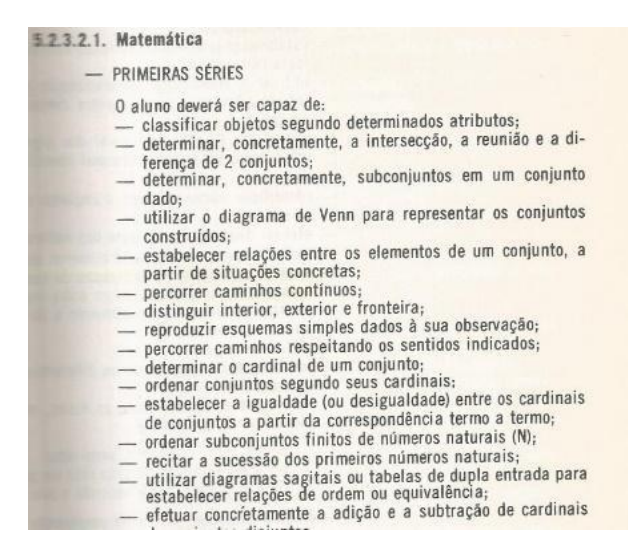

Figura 1 - Laboratório de Currículo

Fonte: Rio de Janeiro, 1976, p. 159.

Ainda na Unicamp, Noronha percebeu que a forma mais acessível para atingir todos os professores do estado do Rio de Janeiro com as práticas que estavam sendo desenvolvidas no LC era a de gravar videotapes. A ideia era filmar algumas aulas, para que os professores observassem os videotapes e entendessem como funcionava uma aula ativa, que, em prática, seria: "desenvolvimento de estratégias que garantam a organização de um aprendizado mais interativo e intimamente ligado com as situações reais" (Camargo \& Daros, 2018, p. 4).

O tema escolhido por Noronha foi "Funções", que era uma unidade estudada no $1^{\circ} \mathrm{grau}$, devido a sua grande aplicação a diferentes níveis e áreas da matemática. Segundo ela, os videotapes sobre funções teriam como objetivos: 
Modificar a sistemática do treinamento de professores, desenvolver um sistema para aperfeiçoamento e/ou atualização em Educação matemática dos professores da Rede Estadual de Ensino do $1^{\circ}$ Grau do Rio de Janeiro, em tempo hábil, elaborar um modelo de curso de treinamento nos aspectos pedagógico e matemático que atenda as necessidades decorrentes das diretrizes da proposta Metodológica do Estado do Rio de Janeiro, utilizando vídeo tapes, propiciar ao professor a dinâmica desenvolvida em aulas ativas e fornecer modelo de curso de treinamento aos Centros Regionais de Educação e Cultura e aos Núcleos Comunitários de Educação e Cultura. (Noronha, 1980, p. 27)

Definidos os objetivos e sob orientação do professor Caban ${ }^{15}$, decidiram primeiro criar um roteiro para uma gravação de 5 a 7 minutos. A gravação foi feita com uma pequena câmera portátil e numa sala de aproximadamente $5 \mathrm{~m}^{2}$, com o auxílio de colegas do curso de mestrado, que simulavam os alunos, de modo a demonstrar a interação professor-aluno. Conforme Noronha, a primeira fase foi um sucesso e a partir daí decidiram elaborar um curso completo de treinamento de professores (Live, 2020). Para isso, analisou-se a produção dos roteiros, determinação do tempo de observação real do indivíduo, manejo do equipamento e levantamento de custos e recursos existentes na SEEC/RJ. O resultado dessa organização foi que:

Cada curso se constituiria de uma série de módulos cobrindo um conteúdo de matemática ensinado no $1^{\circ}$ Grau por um professor que, partindo de situações concretas propostas aos alunos, os orienta para uma sistematização, até que eles mesmos cheguem à descoberta do conceito matemático subjacente. (Noronha, 1980, p. 30)

No final desse curso, o professor deveria montar um planejamento de aula baseado na nova metodologia, usando o material concreto necessário para o desenvolvimento. Além dos textos, os professores cursistas receberam bibliografias sobre o conteúdo e a metodologia estudada. No que se referia à distribuição desse material em todo o estado do Rio de Janeiro, Noronha revela três opções de como esses professores receberiam e aplicariam esses recursos:

${ }^{15}$ Professor da Unicamp e especialista em tecnologias educacionais (Noronha, 1980). 
[1] A instalação de monitores de vídeo-cassete nos CREC's (Centros Regionais de Educação e Cultura), o que permitiria a realização de cursos de treinamento nestes centros, o que já significaria uma descentralização; [2] a emissão dos vídeo-tapes em circuito aberto aproveitando horários ociosos na TVE (Televisão Educativa). Neste caso, os professores cursistas poderiam ser reunidos em turmas em qualquer escola que dispusesse de um receptor de televisão, ou receber na sua escola o material escrito correspondente e fazer o curso em sua própria casa, enviando a avaliação final para o CREC a que está subordinado; [3] a transformação dos vídeo-tapes em filmes. Processo mais barato que a filmagem direta e que permitiria a realização dos cursos de treinamento nas escolas que já possuem projetor de filmes. (Noronha, 1980, p. 33)

Por questão orçamental, a ideia que seguiu adiante foi a de utilizar a televisão educativa como estimulador da criatividade, fazendo com que o telespectador fosse ativo, eliminando a ideia de produzir um telespectador passivo que somente assiste à televisão.

Depois do seu trabalho no Laboratório de Currículos, Noronha continuou trabalhando na formação de professores para atuarem no $1^{\circ} \mathrm{grau}$, como mostra 0 noticiário do Jornal do Brasil (1989), sempre seguindo que estava diretamente alinhada com as ideias defendidas pelo Movimento da Matemática Moderna (MMM).

\section{Algumas CONSIDERAÇõES}

Retomando nossas questões iniciais: De que maneira Diva Noronha colaborou para a produção de saberes profissionais docentes para os professores das séries iniciais no LC do estado do Rio de Janeiro? Que contextos de sustentação possibilitaram as propostas de Noronha? Quais as propostas gerais de Noronha?

Após nosso estudo operando uma análise contextual do período demarcado a respeito dos problemas nas séries iniciais, destacando a deficiência dos programas de ensino e as lacunas na formação docente em relação aos saberes para ensinare os saberes a ensinar, podemos dizer que, de maneira geral, a LDB 5.692 (1971) trouxe a oportunidade e a exigência de manifestar aquilo que se propunha o Estado para atender as especificidades e necessidades do aluno/escola para desenvolver a política econômica do país, através da profissionalização qualificada de baixo custo para as indústrias. 


\section{Universidade Federal da Grande Dourados}

Sobre o ensino de matemática no estado do Rio de Janeiro, podemos dizer que Diva Noronha, a convite do Estado para solucionar problemas técnicos, coordenou a equipe de matemática para as séries iniciais do Laboratório de Currículo, produzindo transformações da matemática, seja ela para/a ensinar, visto que a responsabilidade da equipe era de reformular o ensino do Estado implementando novos conteúdos e abordagens, que, de algum modo, viriam a modificar a concepção do docente sobre o ensino de matemática.

De modo geral, os saberes a/para ensinar sistematizados por Noronha no documento analisado consideravam a matemática como uma estrutura. Assim, o programa do LC desenvolveu um sistema de cursos, de modo a oportunizar, através de aulas em videotapes, a formação nos novos conteúdos e abordagens apregoados pelo LC da rede estadual de ensino do Rio de Janeiro. A utilização de vídeo aulas, de acordo com Noronha, viabilizou a participação de muitos docentes, visto que poderiam ser assistidas em qualquer local. Além disso, as aulas propostas tinham como pressupostos uma aula dinâmica e ativa, com materiais concretos.

Assim, os cursos gravados em videotapes desenvolvidos pelo LC foram distribuídos em todo o estado do Rio de Janeiro, sendo entregues aos Centros Regionais de Educação e Cultura, para que os professores cursistas pudessem se reunir em qualquer escola que dispusesse de um receptor de televisão. Já para os materiais escritos, havia a possibilidade de o professor receber o material na sua escola para que pudesse ser feito o curso em sua própria casa. Dessa forma, podemos constatar que os saberes abordados nos cursos de formação de professores foram circulados e sistematizados em toda a rede de ensino do Estado.

Nessa perspectiva piagetiana e estruturalista, novos modos fizeram-se necessários, constituindo-se uma série de módulos cobrindo um conteúdo de matemática, partindo de situações concretas propostas aos alunos, com as devidas orientações para sua sistematização, até que eles mesmos chegassem à descoberta do conceito matemático implícito.

Logo, constatamos que, por sua expertise profissional - adquirida por sua formação e práticas de ensino vivenciadas no ambiente escolar e empregada no 
Laboratório de Currículos a pedido do Estado -, podemos caracterizar Diva Maria Noronha como uma expert na formação de professores, que buscou solucionar o problema do desnível da matemática para/a ensinar do corpo docente do estado do Rio de Janeiro com um método ativo por meio de videotapes.

Quanto aos saberes produzidos por Noronha, identificamos que a metodologia proposta deveria ser acessível à faixa etária atendida, numa abordagem que valorizasse as estruturas matemáticas e que explorasse conhecimentos abstratos, em consonância com o desenvolvimento psicológico.

De acordo com França e Zuin (2020), os saberes a/para ensinar matemática, nas décadas de 1960 e 1970, foram produzidos em grupos de estudos de professores que se aglutinavam para estudar e produzir saberes, baseados em Piaget e Brunner, teóricos que fundamentavam o ideário do MMM. Assim, a aprendizagem, vista como processo global, abrangeria o desenvolvimento intelectual de habilidades e atitudes. O MMM propunha novos conteúdos e também outras formas de organizar esses conteúdos. Nesse sentido, revisava a concepção estrutural da matemática, dando ênfase às funções e às relações interligadas pela teoria dos conjuntos, iniciando pelas estruturas matemáticas simples. Observamos que Noronha procurou didatizar essas ideias, abordando as atividades de classificação e seriação.

Assim, as análises iniciais indicam a produção de saberes docentes com influência da psicologia e pedagogia, assim como orientações para professores que revelam uma matemática para ensinar cognitivista, respeitando o desenvolvimento mental das crianças.

\section{AGRADECIMENTOS}

Agradecemos ao Conselho Nacional de Desenvolvimento Científico e Tecnológico (CNPQ) pelo financiamento da pesquisa em nível de Iniciação Científica, processo $\mathrm{n}^{\circ}$ 121237/2020-6. 


\section{Universidade Federal da Grande Dourados}

\section{REFERÊNCIAS}

Borry, M. (2020). Les paradoxes de l'expert: Comprendre les limites de la connaissance et de l'expérience. Paris: L'Harmattan.

Correio da Manhã. (1971, março 1). Educação. Rio de Janeiro, Edição 23887, Anexo, p. 7. Recuperado em 17 de janeiro, 2021, de http://memoria.bn.br/docreader/089842_08/17633

Faria, L., \& Lobo, Y. (2005). Memórias e discursos: a escola fluminense pós-fusão (1975-1983). Cadernos de História da Educação, 4, 103-116. Recuperado de http://www.seer.ufu.br/index.php/che/article/view/389

França, D. M. (2019). Matemática nas séries iniciais: o que mudou?. Curitiba: Appris.

França, D. M. (2020, maio). Afro do Amaral Fontoura: a sistematização de saberes aritméticos para os cursos de formação de professores da Guanabara. Anais do Seminário Temático: os experts e a sistematização da matemática para o ensino e formação de professores, Cuiabá. Mato Grosso, Brasil, 18.

França, D. M., \& Maciel, P. R. C. (2020). Diva Noronha: uma expert da educação para séries iniciais no período do Movimento da Matemática Moderna (1975-1987). REMATEC, 15(34), 70-91. http://dx.doi.org/10.37084/REMATEC.19803141.2020.n34.p70-91.id263 


\section{Universidade Federal da Grande Dourados}

França, D. M. A., \& Zuin, E. S. L. (2020). Saberes profissionais para ensinar matemática na década de 1960 o caso dos ginásios vocacionais a partir da literatura cinzenta. Revista Brasileira de História da Educação, 20, 1-27.

Hofstetter, R., Schneuwly, B., \& Freymond, M. (2017). Penetrar na verdade da escola para ter elementos concretos de sua avaliação: a irresistível institucionalização do expert em educação (século XIX e XX). In R. Hofstetter \& W. R. Valente (Org.), Saberes em (trans)formação: tema central da formação de professores (Vol. 1, pp. 55-112). São Paulo: Editora Livraria Física.

Jornal do Brasil. (1989, julho 24). Matemática. Rio de Janeiro, Edição 107, Caderno Cidade, p. 4. Recuperado em 25 de janeiro, 2021, de http://memoria.bn.br/DocReader/DocReaderMobile.aspx?bib=030015_10\&pesq =\%22Diva\%20Noronha\%22\&pasta=ano\%20198

Lei n. 5.692, de 11 de agosto de 1971 (Lei de Diretrizes e Bases da Educação Nacional; LDB) (1971). Fixa Diretrizes e Bases para o ensino de $1^{\circ}$ e $2^{\circ}$ graus, e dá outras providências. Recuperado de https://www2.camara.leg.br/legin/fed/lei/1970-1979/lei-5692-11-agosto-1971357752-publicacaooriginal-1-pl.html

Live com Diva Noronha (2020, dezembro 30). [Vídeo]. Recuperado de https://www.youtube.com/watch?v=Elv8XvYhbk8\&feature=youtu.beManuela. 


\section{Universidade Federal da Grande Dourados}

Noronha, D. M. B. (1980). Proposta de solução para atualização dos professores da rede estadual de ensino no Rio de Janeiro em matemática, utilizando videotapes (Dissertação de mestrado). Universidade Estadual de Campinas, Instituto de Matemática, Estatística e Ciência da Computação, Campinas, SP, Brasil.

O Fluminense. (1970, janeiro 5). Centro educacional expõe os planos para 70. Niterói, Edição 20631, 1ํ Caderno, p. 6. Recuperado em 25 de janeiro, 2021, de http://memoria.bn.br/DocReader/DocReader.aspx?bib=100439_11\&pesq=Labor at\%C3\%B3rio\%20de\%20curr\%C3\%ADculo\%20Myrthes\%20de\%20Luca\%20W enzel\&pasta=ano\%20197\&pagfis $=73132$

O Fluminense. (1971, dezembro 2). Posição do Centro Educacional em face da Reforma do Ensino. Niterói, Edição 20939, º Caderno, p. 3. Recuperado em 26 de janeiro, 2021, de http://memoria.bn.br/DocReader/DocReader.aspx?bib=100439_11\&pesq=Labor at\%C3\%B3rio\%20de\%20curr\%C3\%ADculo\%20Myrthes\%20de\%20Luca\%20W enzel\&pasta=ano\%20197\&pagfis $=1456$

Ramos, G. M. (2011). Uma história do ensino da matemática nas séries iniciais do colégio Pedro II (1984 - 2009) (Tese de doutorado). Universidade Bandeirante de São Paulo, SP, Brasil.

Rio de Janeiro. (1976). Laboratório de Currículos. Reformulação Curricular do Estado do Rio de Janeiro. Subsídios para a organização curricular do ensino de 1ํo grau do Rio de Janeiro - 1aㅗ série. Rio de Janeiro: Imprensa Oficial do Estado. 


\section{Universidade Federal da Grande Dourados}

Valente, W. R. (2019). Que matemática para formar o futuro professor? História do saber profissional do professor que ensina matemática. Revista Exitus, 9(2), 1525. http://dx.doi.org/10.24065/2237-9460.2019v9n2ID852

Villela, L. M. A., Lacava, A. G., Costa, D. A., Franca, D. M. A., \& Salvador, H. H. de F. (2016). Os experts dos primeiros anos escolares: a construção de um corpo de especialistas no ensino de Matemática. In N. B. Pinto \& W. R. Valente (Org.), Saberes Elementares Matemáticos em Circulação no Brasil (p. 245-253). São Paulo: Editora Livraria Física.

\section{CONTRIBUIÇÕES DOS AUTORES}

1ํ autor: conceitualização; curadoria de dados; análise formal; investigação; metodologia; redação - rascunho original; redação - revisão e edição.

2o autor: conceitualização; curadoria de dados; análise formal; investigação; metodologia; redação - rascunho original; redação - revisão e edição.

3o autor: análise formal; administração do projeto; supervisão; visualização; redação - revisão e edição. 